\title{
Cardiac Parameters and Interleukin-6 Differences between Adolescents with Hepatitis B Infection versus those Complicated with Hepatocelluar Carcinoma
}

\author{
Waleed Mohamed Elguindy ${ }^{1}$, Sameh M. Abdel Monem ${ }^{2}$, \\ Hosam El Din Mostafa Seleem ${ }^{3}$ and Thoraya Hosny ${ }^{4}$ \\ ${ }^{1}$ Pediatric Department, Faculty of Medicine, Ain Shams University, Cairo, Egypt \\ ${ }^{2}$ Tropical Medicine Department, Faculty of Medicine, Zagazig University, Egypt \\ ${ }^{3}$ Tropical Medicine Department, Faculty of Medicine, Menofia University, Egypt \\ ${ }^{4}$ Clinical pathology Department, Faculty of Medicine, Zagazig University, Egypt
}

Corresponding Author

Sameh Mahmoud

Abdel-Monem

Mobile:

$+201000641647$

E mail:

drsameh154@yahoo.c om

Key words:

Hepatitis B

hepatocellular

carcinoma,

Adolescents, IL6,

Anthropometry,

Echocardiography
Background and study aim: Hepatitis B virus (HBV) is a major risk factor of hepatocellular carcinoma (HCC) in all age groups. There is a need to differentiate between them in the adolescence age by laboratory and physical examination for assessment of different outcomes of both diseases.

Subjects and Methods: Cross sectional study that included 24 adolescents with $\mathrm{HBV}$, another 24 with $\mathrm{HCC}$ with age ranging from 12 and up to 17 years. They were selected from those admitted to Tropical Medicine Department, Menofia University and Tropical Medicine Department, Zagazig University. All patient underwent laboratory assessment of interleukin6 (IL6) and were further examined at the Cardiology Unit

\section{INTRODUCTION}

Liver cancer is the second most common cause of cancer-related deaths worldwide, and there are approximately 850,000 new cases per year worldwide [1,2]. Unlike HCC in adults, which commonly arises in the setting of prolonged chronic hepatitis and cirrhosis, tumors in adolescents have been observed with HBV infection acquired perinatally or due to inherited metabolic disorders [3]. In Egypt, HCC had been accounted for nearly $4.7 \%$ of chronic liver disease (CLD) patients $[4,5]$. The incidence of new cases is about $500000-1000000$ annually, giving rise to 600000 deaths globally per year [6-8].

Hepatitis B virus (HBV) infection is a major public health problem worldwide. in Pediatric department of Ain Shams University hospitals for complete echocardiographic and anthropometric evaluation.

Results: Twenty four patients have HCC were examined with mean age (14.15 \pm 3.01) years and another 24 are having HBV (14.64 \pm 3.13$)$ years. Differences were found between both groups as regards IL6 as mean values were $(13.29 \mathrm{pg} / \mathrm{ml})$ in HBV and $(77.63 \mathrm{pg} / \mathrm{ml})$ in $\mathrm{HCC}$ group while no differences were detected as regards cardiac and anthropometric evaluations.

Conclusion: IL6 seems to be a useful marker to compare between HBV and HCC in adolescent patients instead of depending on clinical cardiac evaluation or growth parameters that showed no differences.
Hepatitis B is an infectious disease, associated with an estimated 350 million chronically infected patients [9]. Recently, there has been recognition of the recognized significance of $\mathrm{HBV}$ infection in hypertrophic or dilated cardiomyopathy and myocarditis patients [10]. It is also thought that there is a relation between HBV and coronary artery disease. Conflicting findings on the possible association between HBsAg-positivity, indicating inactive HBsAg carrier status, and atherosclerosis have been reported [11,12]. Also, it is known that liver diseases are associated with abnormalities in cardiac geometry and function in adults (cirrhotic cardiomyopathy) but rarely explored in cirrhotic infants or children [13]. 
The most commonly used screening tests for HCC are serum alpha feto-protein (AFP) and ultrasonography. However, the results of the AFP screening in adolescents have not been satisfactory, with a sensitivity of $39 \%$ and specificity of $76 \%$, when using $20 \mathrm{ng} / \mathrm{mL}$ as a cutoff value [14]. The role of using an AFP measurement for screening or diagnosis of HCC has not been precisely investigated for adolescents who developed HCC associated with chronic HBV infection

Finally, chronic HBV can be differentiated by a chronic inflammatory state in the liver with an elevated output of pro-inflammatory cytokines like interleukin 6 (IL-6) [15]. The inflammatory cytokine, IL-6, is a cytokine with several functions that performs a master role in the reply of hepatic epithelia to inflammation [16]. Therefore, the existing project was done to estimate the cardiac functions and grades of IL- 6 in adolescents with $\mathrm{HCC}$ and HBV.

\section{SUBJECTS AND METHODS}

The current project is a comparative crosssectional study of subjects who visited the Tropical Medicine Department Menofia University and Tropical Medicine Department Zagazig University from attendants of outpatient clinic and from inpatients at the time between September 2012 to April 2017 with the approval of the ethical committee of Tropical Medicine Department Menofia University and Tropical Medicine Department Zagazig University. 24 patients (12 males and 12 females) diagnosed as chronic HBV by detectable HBsAg for greater than six months with anti $\mathrm{HBc} \operatorname{IgG}+\mathrm{ve}$ and proved by quantitative PCR; another 24 patients (13 males and 11 females) have HCC on top of chronic HBV infection. HCC diagnosed based on Alpha feto-protein (AFP), pelvi-abdominal ultrasound and confirmed with triphasic CT based on AASLD guidelines [17]. Both groups were subjected to the following: Full medical history taking and Complete clinical examination. Liver functions test (serum albumin, serum bilirubin (total and direct), ALT \& AST using colorimetric method). kidney functions test (Serum creatinine and blood urea nitrogen (BUN) by colorimetric method) and Complete blood count (Hemoglobin, white blood cells and platelets using automated blood counter). Blood samples for the measurement of serum IL-6 levels were collected via venipuncture performed between 8:00 and 12:00 AM. Blood IL-6 grades were detected utilizing the ELISA using a commercial kit (Ray Biotech, Inc., USA). Also, cardiac assessment by Echocardiography (2D) and ECG was done at the Cardiology Unit in Pediatric department of Ain-Shams University hospitals to assess both systolic and diastolic functions, cardiac geometry, dimensions and Cardiac Index that relates the cardiac output (CO) from left ventricle in one minute to body surface area (BSA) were also assessed.

\section{Exclusion criteria :}

- Patients with chronic hepatitis C

- Patients with chronic liver disease due to any cause rather than chronic hepatitis B

- Patients with HCC due to any cause rather than chronic hepatitis B

- Patients with congenital heart diseases

\section{Statistical analysis}

Data were checked, entered and analyzed using SPSS 22 for Windows. Data were expressed as mean \pm SD for quantitative variable, number and percentage for qualitative one. Chi-squared (X2) or $\mathrm{t}$ test and paired $\mathrm{t}$ test were used when appropriate. $\mathrm{P}<0.05$ was considered significant. $\mathrm{P}<0.001$ was considered high significant.

\section{RESULTS}

The current study documented that 24 patients of HCC (13 males and 11 females) were examined with mean age $(14.15 \pm 3.01)$ years and another 24 having HBV (12 males and 12 females) with mean age (14.64 \pm 3.13$)$ years.

Statistically significant difference between HCC and HBV patients was found in relation to IL-6 $(\mathrm{p}=0.001)$ (Table 1). It was noticed that no differences were found between the 2 previous groups in relation to $\mathrm{Z}$ scores of left atrial diameter, left ventricle mass, left ventricular end diastolic diameter, posterior wall thickness and interventricular septum in diastole as $(\mathrm{p}=0.424$, $0.075,0.120,1.000$ and 0.369 respectively) (Table 2).

Also, comparing both echocardiographic functions between the studied groups (Tables 3,4) no significant differences were found regards both systolic functions; ejection fraction, fraction shortening, stroke volume, cardiac output, end diastolic volume and cardiac index where $(\mathrm{p}$ value $=0.351,0.3120 .799,0.851,0.706$, and 
$0.212)$. and diastolic functions; E/A ratio where $(\mathrm{p}$ value $=0.604)$

But in Table 5 shows significant difference between corrected QT interval in both groups as the mean QTc interval in HCC patients was $(0.46 \pm 0.04)$ that is mildly elevated and in $\mathrm{HBV}$ patients $(0.42 \pm$ $0.02)$ that is in normal range as $p$ value $=(0.039)$.
Moreover table 6 shows that no statistically significant differences were found between the 2 studied groups as regards anthropometric measurements as in comparison of the 2 groups regards $\mathrm{Z}$ scores of body weight, height and body mass index as ( $\mathrm{p}$ value $=0.6 \cdot \mathrm{r}, 0.892$ and 0.904$)$

Table (1): Serum IL-6 levels among the studied groups

\begin{tabular}{|l|c|c|c|}
\hline \multicolumn{1}{|c|}{ Groups } & HBV patients without HCC & HCC patients & P value \\
\hline $\begin{array}{l}\text { IL-6 }(\mathrm{pg} / \mathrm{ml}) \\
\text { Mean } \pm \text { SD }\end{array}$ & $13.29 \pm 2.67$ & $77.63 \pm 13.09$ & 0.001 \\
\hline
\end{tabular}

Table (2) : Echocardiographic parameters between the studied groups

\begin{tabular}{|l|c|c|c|c|}
\hline \multirow{2}{*}{ Echocardiographic parameters } & \multirow{2}{*}{ HCC patients } & \multirow{2}{*}{ HBV patients } & \multicolumn{2}{|c|}{ Mann-Whitney Test } \\
\cline { 3 - 5 } & & & $\mathbf{Z}$ & P-value \\
\hline zLAD & 1.62 & -0.23 & 0.833 & 0.424 \\
\hline zLVM & 0.72 & 0.38 & 1.71 & 0.075 \\
\hline zLVEDD & 1.02 & 0.08 & 1.621 & 0.120 \\
\hline zPWD & 1.29 & 1.63 & 0.000 & 1.000 \\
\hline zIVS & 1.42 & 0.67 & 0.892 & 0.369 \\
\hline
\end{tabular}

zLAD: Z score of left atrial diameter, zLVM: Z score of left ventricle mass, zLVEDD: Z score of left ventricular end diastolic diameter, zPWD: Z score of posterior wall thickness, zIVS Z score of interventricular septum

Table (3) : Comparison between systolic functions between the studied groups

\begin{tabular}{|l|c|c|c|c|}
\hline Echocardiographic & HBV patients & HCC patients & \multirow{2}{*}{ T } & \multirow{2}{*}{ P value } \\
\cline { 2 - 3 } Systolic Functions & Mean $\mathbf{\text { SD }}$ & Mean \pm SD & & \\
\hline EF \% & $69 \pm 6$ & $71 \pm 8$ & 0.955 & 0.351 \\
\hline FS \% & $37 \pm 5$ & $40 \pm 6$ & 1.059 & 0.312 \\
\hline SV $(\mathbf{m l})$ & $42 \pm 21$ & $40 \pm 19$ & 0.211 & 0.799 \\
\hline CO $(\mathbf{L} / \mathbf{m i n})$ & $4.15 \pm 2.54$ & $4.23 \pm 2.45$ & 0.298 & 0.851 \\
\hline EDV $(\mathbf{m l})$ & $60 \pm 34$ & $61 \pm 29$ & 0.396 & 0.706 \\
\hline CI $\left(\mathbf{L} / \mathbf{m i n} / \mathbf{m}^{2}\right)$ & $4.71 \pm 2.18$ & $5.72 \pm 2.54$ & 1.265 & 0.212 \\
\hline
\end{tabular}

t- Independent sample t-test was used in that comparison. EF: ejection fraction, FS: fraction shortening, SV: stroke volume, CO: cardiac output, EDV: end diastolic volume, CI: cardiac index

Table (4) : Comparison between diastolic functions between the studied groups

\begin{tabular}{|l|c|c|c|c|}
\hline \multirow{2}{*}{$\begin{array}{l}\text { Echocardiographic } \\
\text { Diastolic Functions }\end{array}$} & HBV patients & HCC patients & \multirow{2}{*}{ T } & \multirow{2}{*}{ P value } \\
\cline { 2 - 3 } & Mean \pm SD & Mean \pm SD & & \\
\hline E/A ratio & $1.74 \pm 1.1$ & $1.99 \pm 1.54$ & 0.488 & 0.604 \\
\hline
\end{tabular}

$\mathrm{t}$ - Independent sample t-test was used in that comparison. $\mathrm{P}$ value considered significant if $<0.05$. 
Table (5) : Comparison between the studied groups as regards increased QTc interval

\begin{tabular}{|l|c|c|c|c|}
\hline \multirow{2}{*}{ ECG } & HBV patients & HCCpatients & T & P value \\
\cline { 2 - 3 } & Mean \pm SD & Mean \pm SD & \\
\hline $\begin{array}{l}\text { QTc } \\
\text { interval }(\mathrm{Sec})\end{array}$ & $0.42 \pm 0.02$ & $0.46 \pm 0.04$ & 2.210 & 0.039 \\
\hline
\end{tabular}

t- Independent sample t-test was used in that comparison. $\mathrm{p}$ value considered significant if $<0.05$.

Table (6) : Comparison of the anthropometric measurements of the studied groups

\begin{tabular}{|c|c|c|c|c|}
\hline \multirow{2}{*}{ Anthropometric measurements } & \multirow{2}{*}{ HBV patients } & \multirow{2}{*}{ HCC patients } & Mann-Whitney Test \\
\cline { 5 - 5 } & & & P-value \\
\hline zWeight & Median (IQR) & $-0.17(1.26)$ & $-0.21(1.32)$ & 0.602 \\
\hline zHeight & Median (IQR) & $-0.137(1.83)$ & $-0.14(1.89)$ & 0.892 \\
\hline zBMI & Median (IQR) & $-0.149(1.22)$ & $-0.153(1.32)$ & 0.904 \\
\hline
\end{tabular}

IQR: interquartile range, zBMI: $\mathrm{Z}$ score of body mass index

\section{DISCUSSION}

HCC is a major health problem in Egypt and its incidence is increasing [18]. According to the National Institute of Cancer (NIC) in Egypt, HCC is considered one of the most common malignancies in Egypt as a result of the high prevalence of viral hepatitis infections, since these represent approximately $45.3 \%$ of all new cases of this cancer type [19].

Hepatitis B virus (HBV) is considered moderately endemic in Egypt with $4 \%$ of the population having evidence of chronic HBV infection [20]. A key goal of HBV immunization program is to reduce the prevalence of hepatitis $B$ surface antigen (HBsAg) among cohorts born since the program implementation in 1992. However, in this study the number of adolescents with chronic HBV and $\mathrm{HCC}$ on top of HBV is relatively high, may be due to high perinatal transmission with lake of immunoglobulin administration due to high cost or unavailability as most of the studies population were from rural areas where the tradition of home delivery is still ongoing.

Collected guide mark that sustained inflammatory reaction is the master sharing agent to $\mathrm{HCC}$ expansion in chronic hepatitis B patients [21]. Several inflammatory cytokines included tumor necrosis factor (TNF)-a, IL-1a, IL-1b, IL-6, and IL-8, were involved in chronic liver inflammation, among IL-6 is thought the mostly important one, also cardiac affection thought to differ between hepatitis B and HCC [22,23]. In the current study, slightly increase grades of serum IL-6 were associated with the HBV-infected group. This outcome came in approval with findings of a Chinese study which showed that serum grade of
IL-6 was significantly elevated in all HBV-infected patients with compare to control group [24]. In this study, marked raise grades of serum IL-6 were associated with the HCC infected group. IL-6 intracellular signaling includes a complex network of several pathways [25-27]. One study showed that IL- 6 grades were raised in the patients with chronic liver disease that included cirrhosis and HCC [28]. However, IL-6 grades were marked elevated in HCC patients with comparison to cirrhotic patients without cancer.

The existing results were in accordance with many other studies [29-31] that showed that IL-6 grades in patients with $\mathrm{HCC}$ were elevated than those chronic hepatitis patients, on the other hand the current results were not consistent with GhaderiZefrehi [32], who displayed that IL-6 grades were a little elevated only in asymptomatic hepatitis carriers than those in controls but normal in both chronic hepatitis patients and HCC patients.

Importantly, no major differences were found in all echocardiographic parameters between Hepatitis $\mathrm{B}$ patients and HCC group including systolic and diastolic functions even most of the data remains similar to the normal healthy population unlike [13] who stated that cirrhotic liver diseases are associated with abnormalities in cardiac geometry and function in adults, unfortunately we found no other previous studies to compare our results with in adolescents, on the contrary there was a significant difference regards corrected QT interval during ECG study between the 2 groups as $p$ value $=(0.043)$, thought both values $(0.45$ and 0.42 $\mathrm{Sec})$ remains in the normal range and theoretically tends to resolve with treatment, also during comparison of the anthropometric measurements 
no statistically significant differences were found between $\mathrm{Z}$ scores of body weight, height and body mass index. These results need to be confirmed by further studies even if it was in agreement with Desai et al. [13] as different liver conditions tend to affect the growth velocity in the adolescence stage of life.

\section{CONCLUSION}

We could find out from our study and based upon these findings that cardiac and anthropometric evaluation have failed to compare and differentiate between Hepatitis B and HCC in adolescents, though instead we can rely on biological markers that showed to be helpful as IL6.

Funding: None.

Conflicts of interest: None.

Ethical approval:Approved ; written consents have been taken from all included patients.

\section{REFERENCES}

1. Torre LA, Bray F, Siegel RL, Ferlay J, LortetTieulent $\mathbf{J}$ and Jemal A. Global cancer statistics, 2012. CA: a cancer Journal for Clinicians. 2015;65(2):87-108.

2. Llovet JM, Zucman-Rossi J, Pikarsky E, Sangro B, Schwartz M, Sherman M, et al. Hepatocellular carcinoma. Nature reviews Disease Primers. 2016;2:16018.

3. McAteer JP, Goldin AB, Healey PJ and Gow KW. Hepatocellular carcinoma in children: epidemiology and the impact of regional lymphadenectomy on surgical outcomes. Journal of Pediatric Surgery. 2013;48(11):2194-201.

4. El-Zayadi AR, Abaza H, Shawky S, Mohamed MK, Selim OE and Badran HM. Prevalence and epidemiological features of hepatocellular carcinoma in Egypt - a single center experience. Hepatology Research. 2001;19(2):170-9.

5. Velázquez RF, Rodriguez M, Navascués CA, Linares A, Pérez R, Sotorríos NG, et al. Prospective analysis of risk factors for hepatocellular carcinoma in patients with liver cirrhosis. Hepatology. 2003; 37(3):520-7.

6. Yeh CT, Chen TC, Chang ML, Hsu CW, Yeh TS, Lee $\mathrm{WC}$, et al. Identification of NV-F virus DNA in hepatocellular carcinoma. Journal of Medical Virology. 2007;79(1):92-6.

7. Blachier M, Leleu H, Peck-Radosavljevic M, Valla D-C and Roudot-Thoraval F. The burden of liver disease in Europe: a review of available epidemiological data. Journal of hepatology. 2013; 58(3):593-608.

8. Pascual S, Herrera I and Irurzun J. New advances in hepatocellular carcinoma. World Journal of Hepatology. 2016;8(9):421-38.

9. Lavanchy D. Hepatitis B virus epidemiology, disease burden, treatment, and current and emerging prevention and control measures. $J$ Viral Hepat. 2004;11(2):97-107.

10. Kuhl U, Pauschinger M, Seeberg B, Lassner D, Noutsias M, Poller W, et al. Viral persistence in the myocardium is associated with progressive cardiac dysfunction. Circulation. 2005; 112(13): 1965-70.

11. Amirzadegan A, Davoodi G, Boroumand MA, Darabyan S, Dehkordi MR and Goodarzynejad H. Association between hepatitis B surface antibody seropositivity and coronary artery disease. Indian Journal of Medical Sciences. 2007;61(12):648-55.

12. Demir M and Demir C. Effect of hepatitis B virus infection on right and left ventricular functions. Medical Science Monitor : International Medical Journal of Experimental and Clinical Research. 2012;18(9):Cr587-91.

13. Desai MS, Zainuer S, Kennedy C, Kearney D, Goss $\mathbf{J}$ and Karpen SJ. Cardiac structural and functional alterations in infants and children with biliary atresia, listed for liver transplantation. Gastroenterology. 2011;141(4):1264-72. e4.

14. Collier J and Sherman M. Screening for hepatocellular carcinoma. Hepatology. 1998; 27(1):273-8.

15. Dolganiuc A, Norkina O, Kodys K, Catalano D, Bakis G, Marshall C, et al. Viral and host factors induce macrophage activation and loss of toll-like receptor tolerance in chronic $\mathrm{HCV}$ infection. Gastroenterology. 2007;133(5):1627-36.

16. He $\mathrm{G}$ and Karin M. NF- $\mathrm{BB}$ and STAT3-key players in liver inflammation and cancer. Cell Research. 2011;21(1):159-68.

17. Bruix J, Sherman M: American Association for the Study of Liver Diseases. Management of hepatocellular carcinoma: an update. Hepatology 2011; 53(3):1020-1022.

18. Shaker MK, Abdella HM, Khalifa MO, El Dorry AK.: Epidemiological characteristics of hepatocellular carcinoma in Egypt: a retrospective analysis of 1313 cases. Liver Int. 2013; 33(10): 1601-6.

19. Miller FD, Abu-Raddad LJ. Evidence of intense ongoing endemic transmission of hepatitis $\mathrm{C}$ virus in Egypt. ProcNatlAcadSci USA. 2010; 107(33):14757-14762.PMC2930444doi: 10.1073/ pnas.1008877107. Epub 2010 Aug 9. 
20. World Health Organization. Hepatitis B, World Health Organization fact sheet No. 204. 2009. [Accessed 2010 Feb 8] Available from: http:// www.who.int/mediacentre/factsheets/fs204/en/in dex.html

21. Tajiri H, Takano T, Tanaka H, Ushijima K, Inui A, Miyoshi Y, et al. Hepatocellular carcinoma in children and young patients with chronic HBV infection and the usefulness of alpha-fetoprotein assessment. Cancer Medicine. 2016;5(11):310210.

22. Sun B and Karin M. NF- $\mathrm{BB}$ signaling, liver disease and hepatoprotective agents. Oncogene. 2008;27(48):6228-44.

23. Berasain C, Castillo J, Perugorria M, Latasa M, Prieto $\mathrm{J}$ and Avila $\mathrm{M}$. Inflammation and liver cancer. Annals of the New York Academy of Sciences. 2009;1155(1):206-21.

24. Sheng T, Wang B, Wang S, Deng B, Qu L, Qi X, et al. The Relationship Between Serum Interleukin-6 and the Recurrence of Hepatitis B Virus Related Hepatocellular Carcinoma after Curative Resection. Medicine. 2015;94(24).

25. Hsu J-h, Shi Y, Hu L, Fisher M, Franke TF and Lichtenstein A. Role of the AKT kinase in expansion of multiple myeloma clones: effects on cytokine-dependent proliferative and survival responses. Oncogene. 2002;21(9):1391.

26. Shi Y, Hsu J-h, Hu L, Gera J and Lichtenstein A. Signal pathways involved in activation of p70S6K and phosphorylation of 4E-BP1 following exposure of multiple myeloma tumor cells to interleukin-6. Journal of Biological Chemistry. 2002; 277(18):15712-20.

27. Bharti R, Dey $G$ and Mandal M. Cancer development, chemoresistance, epithelial to mesenchymal transition and stem cells: A snapshot of IL-6 mediated involvement. Cancer Letters. 2016;375(1):51-61.

28. Trikha M, Corringham R, Klein B and Rossi J-F. Targeted anti-interleukin- 6 monoclonal antibody therapy for cancer. Clinical Cancer Research. 2003;9(13):4653-65.

29. Hsia C-Y, Huo T-I, Chiang S-Y, Lu M-F, Sun C$\mathrm{L}, \mathrm{Wu} \mathrm{J}-\mathrm{C}$, et al. Evaluation of interleukin-6, interleukin-10 and human hepatocyte growth factor as tumor markers for hepatocellular carcinoma. European Journal of Surgical Oncology (EJSO). 2007;33(2):208-12.

30. Porta C, De Amici M, Quaglini S, Paglino C, Tagliani F, Boncimino A, et al. Circulating interleukin-6 as a tumor marker for hepatocellular carcinoma. Annals of Oncology. 2008;19(2):3538.

31. Dondeti MF, El-Maadawy EA and Talaat RM. Hepatitis-related hepatocellular carcinoma: Insights into cytokine gene polymorphisms. World journal of Gastroenterology. 2016; 22(30):6800.

32. Ghaderi-Zefrehi H, Gholami-Fesharaki M, Sharafi $\mathrm{H}$, Sadeghi F and Alavian SM. The distribution of hepatitis $\mathrm{C}$ virus genotypes in Middle Eastern countries: a systematic review and meta-analysis. Hepatitis Monthly. 2016; 16(9). 